\title{
Wear Behavior of Self-mated Ti-Si-C Composites and Ti-Si-N Composites Slid Without Lubricant
}

\author{
Yuko Hibi ${ }^{*}$ and Takashi Murakami \\ National Institute of Advanced Industrial Science and Technology (AIST), \\ Advanced Manufacturing Research Institute \\ 1-2-1 Namiki, Tsukuba, Ibaraki 305-8564, Japan \\ *Corresponding author: y.hibi@aist.go.jp
}

( Manuscript received 14 March 2008; accepted 7 May 2008; published 16 May 2008 )

\begin{abstract}
To develop lightweight wear-resistant titanium matrix composites, the wear behaviors of three kinds of composites produced from $\mathrm{SiC}$ and titanium (Ti-Si-C composite) and three kinds of composites produced from $\mathrm{Si}_{3} \mathrm{~N}_{4}$, TiN and titanium (Ti-Si-N composite) were evaluated. The composites were slid against themselves without lubricant. The wear of these composites was smaller than that of titanium metal and was influenced by the kind of ceramics in the starting material rather than the amount of the ceramics. The wear resistance of the Ti-Si-N composite was higher than that of the Ti-Si-C composite. Tribo-oxidation took place on the surfaces of the composites during sliding, and the produced oxide abraded and hollowed the Ti-Si-C composite. On the sliding surface of Ti-Si-N composite, however, plastic flow of the oxide was observed.
\end{abstract}

Keywords: titanium matrix composite, silicon carbide, silicon nitride, titanium nitride, wear

\section{Introduction}

The purpose of this study was to develop lightweight wear resistant materials with toughness. A decrease in the weight of the tribo-materials of moving parts appears to lead to a decrease in the energy consumption of the system. Titanium is a lightweight metal with high ductility. The addition of hard ceramic particles to titanium metal and its alloys often improved the wear resistance ${ }^{1-7)}$. Therefore lightweight ceramic-reinforced titanium-matrix composites are being considered as a candidate energy-saving tribo-material. Silicon-based ceramic-reinforced (especially $\mathrm{SiC}$ ) titanium-matrix composites are lightweight materials with good mechanical properties such as high strength and high stiffness ${ }^{8,9)}$. Ceramics-reinforced titanium-matrix composites contain various interfacial reaction layers because the titanium metal reacts with the reinforcements during the production process at high temperature $^{10)}$. In titanium-matrix composites reinforced by silicon-based ceramics such as $\mathrm{SiC}$ and $\mathrm{Si}_{3} \mathrm{~N}_{4}$, interfacial layers that contained various titanium silicides, TiC and TiN were produced ${ }^{11,12}$. Several research groups have investigated the wear behavior of silicon-based ceramic-reinforced titanium-matrix composites under dry conditions. $\mathrm{Si}_{3} \mathrm{~N}_{4}$-reinforced titanium-matrix composites abraded by garnet particles exhibited high abrasion-resistance ${ }^{6)}$ The wear-resistance of a Ti-6Al-4V alloy, modified with $\mathrm{SiC}$ using a laser, was higher than that of a hardened-and-aged Ti-6Al-4V alloy when slid against steel $^{7)}$. The wear-resistance of a SiC-reinforced Ti-6Al-4V composite, which was produced by a hot isostatic press, was lower than that of the Ti-6Al-4V alloy when slid against steel ${ }^{13)}$.

We investigated the wear behaviors of composites produced from mixtures of $\mathrm{SiC}$ and titanium (Ti-Si-C composites), and composites produced from mixtures of $\mathrm{Si}_{3} \mathrm{~N}_{4}$, TiN and titanium (Ti-Si-N composites) in various environments ${ }^{14-19)}$. Under lubricated conditions using water and ethanol, the wear-resistance of the self-mated $\mathrm{Ti}-\mathrm{Si}-\mathrm{C}$ composite was higher than that of the titanium metal ${ }^{14,15)}$. In water and in $3 \mathrm{wt} \% \mathrm{NaCl}$ aqueous solution, the self-mated Ti-Si-N composite exhibited good wear resistance ${ }^{16,17)}$. The wear-resistance of the Ti-Si-N composite disk when slid against a $\mathrm{Si}_{3} \mathrm{~N}_{4}$ ball was also higher than that of a titanium metal disk when slid without lubricant and under lubricated conditions using $\mathrm{n}$-hexane, water and ethanol as lubricants ${ }^{18,19)}$. The adhesion of the Ti component of the Ti-Si-N composite to its $\mathrm{Si}_{3} \mathrm{~N}_{4}$ counterpart took place when slid without lubricant and when lubricated with n-hexane, while adhesive wear was inhibited when lubricated with water and ethanol ${ }^{18,19)}$.

In our study reported in this paper, we evaluated the wear resistance of self-mated Ti-Si-C composites and 
Table 1 Physical and chemical properties of tested materials

\begin{tabular}{|c|c|c|c|c|c|c|c|c|c|c|c|}
\hline \multirow[t]{2}{*}{ Material } & \multicolumn{4}{|c|}{ Starting material (wt\%) } & \multirow[t]{2}{*}{$\begin{array}{l}\text { Density } \\
\left(\mathrm{g} / \mathrm{cm}^{3}\right)\end{array}$} & \multirow[t]{2}{*}{$\begin{array}{l}\text { Young's } \\
\text { modulus } \\
(\mathrm{GPa})\end{array}$} & \multirow[t]{2}{*}{$\begin{array}{l}\text { Hardness } \\
\text { (GPa) }\end{array}$} & \multirow[t]{2}{*}{$\begin{array}{c}\text { Fracture } \\
\text { toughness } \\
\left(\mathrm{MPa} \mathrm{m}^{1 / 2}\right)\end{array}$} & \multirow[t]{2}{*}{$\begin{array}{l}\text { Component of } \\
\text { reaction layer }\end{array}$} & \multicolumn{2}{|c|}{$\begin{array}{c}\text { Surface } \\
\text { roughness Ra } \\
(\mu \mathrm{m})\end{array}$} \\
\hline & $\mathrm{Ti}$ & $\mathrm{SiC}$ & $\mathrm{TiN}$ & $\mathrm{Si}_{3} \mathrm{~N}_{4}$ & & & & & & Pin & Disk \\
\hline Titanium metal & 99.7 & 0 & 0 & 0 & 4.51 & 117 & 1.4 & $* *$ & & 0.031 & 0.038 \\
\hline 90Ti-Si-C composite & 90 & 10 & 0 & 0 & 4.43 & 134 & 3.5 & $* *$ & $\mathrm{TiC}, \mathrm{Ti}_{5} \mathrm{Si}_{3} \mathrm{C}_{\mathrm{x}}$ & 0.041 & 0.058 \\
\hline 80Ti-Si-C composite & 80 & 20 & 0 & 0 & 4.32 & 189 & 4.3 & $* *$ & $\mathrm{TiC}, \mathrm{Ti}_{5} \mathrm{Si}_{3} \mathrm{C}_{\mathrm{x}}$ & 0.113 & 0.079 \\
\hline 60Ti-Si-C composite & 60 & 40 & 0 & 0 & 4.04 & 293 & 7.0 & $* *$ & $\mathrm{Ti}_{3} \mathrm{SiC}_{2}, \mathrm{TiSi}_{2}$ & 0.233 & 0.139 \\
\hline 80Ti-Si-N composite & 80 & 0 & 10 & 10 & 4.51 & 198 & 10.5 & 9.6 & $\mathrm{Ti}_{5} \mathrm{Si}_{3}, \mathrm{TiSi}_{2}$ & 0.043 & 0.108 \\
\hline 70Ti-Si-N composite & 70 & 0 & 10 & 20 & 4.36 & 211 & 10.0 & 14.2 & $\mathrm{Ti}_{5} \mathrm{Si}_{3}, \mathrm{TiSi}_{2}$ & 0.180 & 0.184 \\
\hline 60Ti-Si-N composite & 60 & 0 & 10 & 30 & 4.28 & 246 & 11.0 & 10.3 & $\mathrm{Ti}_{5} \mathrm{Si}_{3}, \mathrm{TiSi}_{2}$ & 0.092 & 0.180 \\
\hline
\end{tabular}

**No crack was observed around the indentation at $490 \mathrm{~N}$.

Ti-Si-N composites slid without lubricant. We report on the wear behavior of titanium metal, three kinds of Ti-Si-C composites, and three kinds of Ti-Si-N composites when slid against themselves without lubricant.

\section{Experimental Procedure}

\subsection{Materials}

The test materials were three kinds of Ti-Si-C composites, three kinds of Ti-Si-N composites and titanium metal (purity: 99.7\% Ti). The physical and chemical properties of these test materials are summarized in Table 1. Fracture toughness was determined by the indentation method ${ }^{20)}$. Composite disks (diameter: $20 \mathrm{~mm}$, thickness: 4 to $5 \mathrm{~mm}$ ) were produced from the starting materials shown in Table 1 by spark plasma sintering at $1300 \sim 1500{ }^{\circ} \mathrm{C}$ and at a pressure of $64 \mathrm{MPa}$. The interfacial reaction layers in the Ti-Si-C composites and Ti-Si-N composites were formed during sintering. The reaction products in the Ti-Si-C composites were $\mathrm{TiC}, \mathrm{Ti}_{5} \mathrm{Si}_{3} \mathrm{C}_{\mathrm{x}}\left(\mathrm{Ti}_{5} \mathrm{Si}_{3}\right.$ phase that dissolves carbon), $\mathrm{Ti}_{3} \mathrm{SiC}_{2}$ and $\mathrm{TiSi}_{2}$. The interfacial reaction layers in the $\mathrm{Ti}-\mathrm{Si}-\mathrm{N}$ composites were composed of $\mathrm{Ti}_{5} \mathrm{Si}_{3}$ and $\mathrm{TiSi}_{2}$. These reaction products were identified by X-ray diffraction (XRD) patterns ${ }^{14,16)}$. The disk surfaces were polished using a 1000-grade diamond grinding wheel. The hemispherical pins ( $\mathrm{r}$ : $2 \mathrm{~mm}$ ) for the sliding tests were formed from the composite disks. Figure 1 shows SEM images of the polished surfaces of the $80 \mathrm{Ti}-\mathrm{Si}-\mathrm{C}$ composite and the 70Ti-Si-N composite.

\subsection{Sliding test}

Sliding tests were performed using a unidirectional
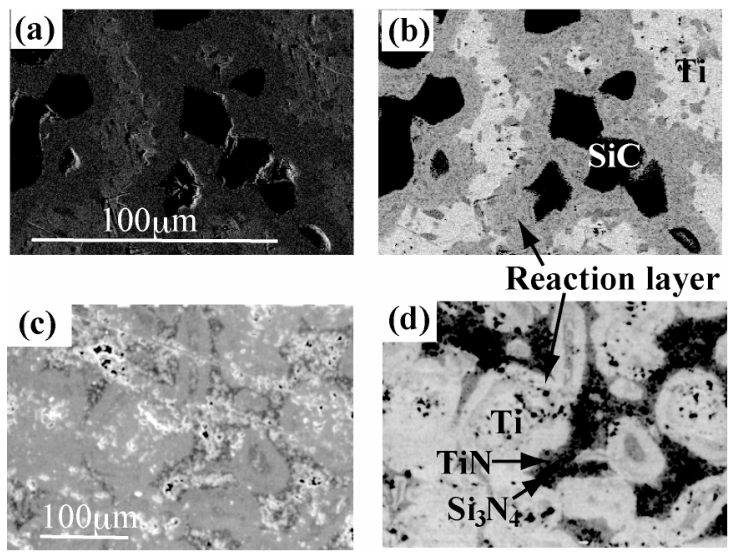

Fig. 1 Scanning electron microscope images of polished surfaces of composites: (a) 80Ti-Si-C composite, (b) back-scattered electron image of (a), (c) 70Ti-Si-N composite, and (d) back-scattered electron image of (c)

pin-on-disk machine (Model 200, Implants Science Corp.). A hemispherical pin of the composite was slid against a disk of the same material without lubricant in atmosphere at room temperature. Humidity was not controlled during sliding test. The applied load was 0.49 $\mathrm{N}$, the sliding speed was $40 \mathrm{~mm} / \mathrm{s}$, the sliding duration was 2 hours and the sliding distance was $288 \mathrm{~m}$. Each test was run at least two times. Morphological observation and elemental analysis of the worn surfaces were performed using a field emission scanning electron microscope (FE-SEM) with energy-dispersive X-ray spectrometers (EDS) and an Electron Probe Micro Analyzer (EPMA). 


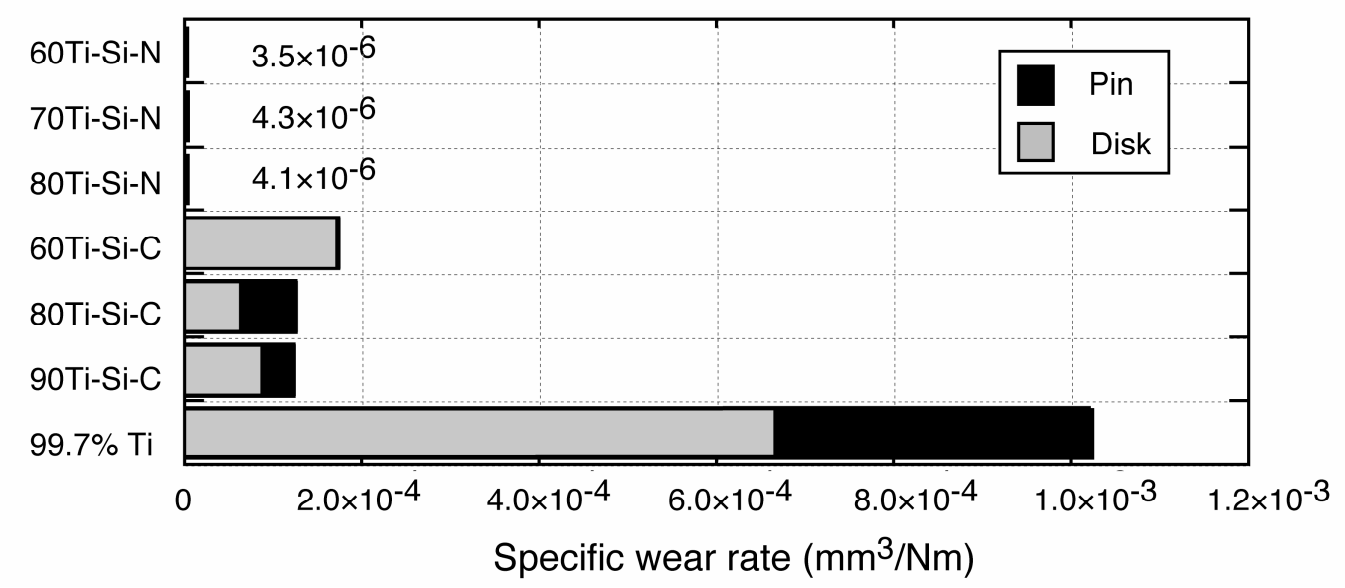

Fig. 2 Specific wear rates of pin and disk of Ti-Si-C composite, Ti-Si-N composite and titanium *The value of 60Ti-Si-C composite: data from reference 15

\section{Results and discussion}

Figure 2 shows the average specific wear rate of the Pin $\left(W s_{\text {pin }}\right)$ and that of the disk ( $\left.W s_{\text {disk }}\right)$ of each of the tested materials. Wear volume of the Ti-Si-N composite disk was too small to be measured. The sum of the $W S$ pin and the $W S$ disk (abbreviated as $W S$ pin \& disk hereafter) of the titanium metal was ca. $1 \times 10^{-3} \mathrm{~mm}^{3} / \mathrm{Nm}$. The $W s$ pin \& disk of the tested composite was smaller than that of the titanium metal. The $W s$ pin \& disk of the composite was influenced by the kind of ceramics in the starting material rather than the amount of the ceramics. The $W s$ pin \& disk of the Ti-Si-C composite was $1.2 \times 10^{-4}$ to $1.7 \times$ $10^{-4} \mathrm{~mm}^{3} / \mathrm{Nm}$, and that of the Ti-Si-N composite was 3.5 $\times 10^{-6}$ to $4.3 \times 10^{-6} \mathrm{~mm}^{3} / \mathrm{Nm}$. The $W S$ pin \& disk of the 80Ti-Si-N composite was $1 / 32$ of that of the 80Ti-Si-C composite. The $W s$ pin \& disk of the $60 \mathrm{Ti}-\mathrm{Si}-\mathrm{N}$ composite was $1 / 49$ of that of the $60 \mathrm{Ti}-\mathrm{Si}-\mathrm{C}$ composite.

Figure 3 shows SEM images of the worn surface of the titanium metal disk. Many grooves along the sliding direction and adhered substances were observed on titanium disk surfaces worn without lubricant (Fig. 3 (a)). EDS analysis revealed that some of the adhered substances (dark area in Fig. 3 (b)) contained high concentrations of oxygen. The atomic percent of titanium of the inside of the rectangle in Fig. 3(b) was $39 \%$, that of oxygen was $55 \%$, and the remainder was carbon derived from contaminants. These results indicated that severe wear and tribo-oxidation occurred on the sliding surface of the titanium, and they accorded with the results of other research groups ${ }^{21,22)}$.

Figure 4 shows SEM images of the 80Ti-Si-C composite disk and pin worn without lubricant. Many scratch grooves along the sliding direction, deposits that adhered to the surface and hollows were observed on the worn disk surfaces of the 80Ti-Si-C composites as shown in Fig. 4 (a), (b) and (c). The chemical composition of the deposits (dark gray area in Fig. 4 (c)) was analyzed using EDS. The atomic percent of titanium of the deposits was
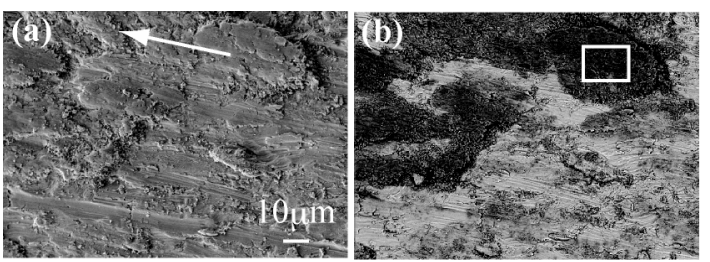

Fig. 3 (a) Scanning electron microscope image of titanium metal disk worn without lubricant, (b) back-scattered electron image of (a). Arrow indicates sliding direction.
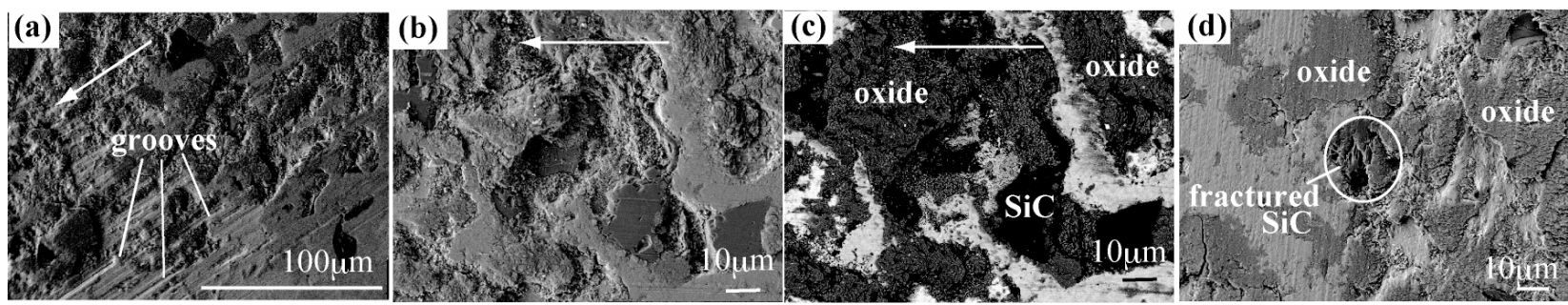

Fig. 4 Scanning electron microscope images of 80Ti-Si-C composite worn without lubricant: (a) worn disk surface,

(b) worn disk surface, (c) back-scattered electron image of (b), (d) worn pin surface. Arrows indicate sliding direction. 

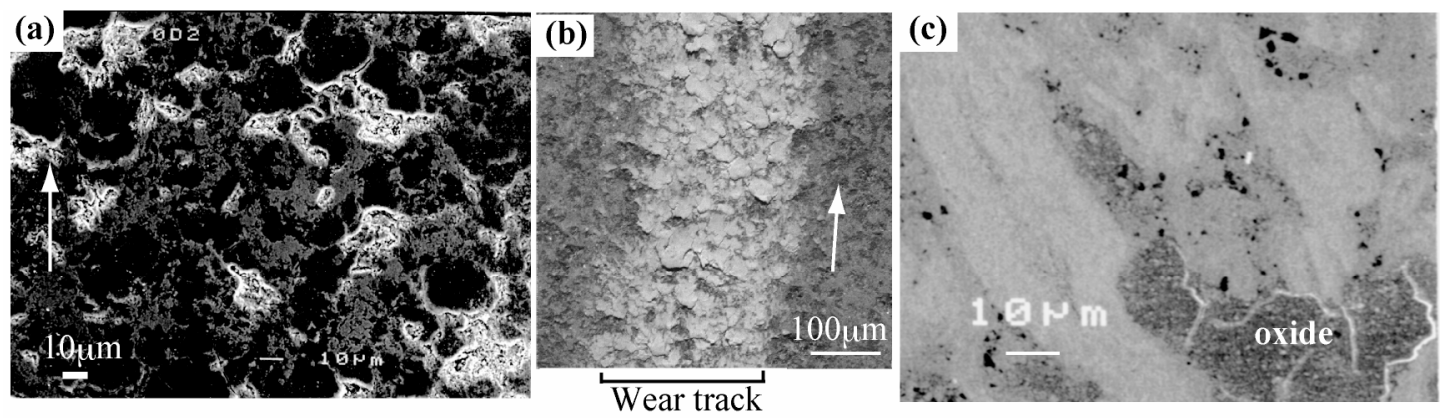

Fig. 5 Surfaces of 70Ti-Si-N composite worn without lubricant: (a) scanning electron microscope image of disk surface, (b) EPMA Ok $\alpha$ image of disk surface, (c) scanning electron microscope image of pin surface. Concentration is expressed in terms of brightness in (b). Arrows indicate sliding direction.

20 to $21 \%$, that of oxygen was 59 to $61 \%$, that of silicon was $6 \%$, and the remainder was carbon. This indicated that the deposits mainly consisted of titanium oxide and silicon oxide. These oxides appeared to have been formed by tribo-oxidation during sliding. Oxides, hollows and fractured $\mathrm{SiC}$ were observed on the worn pin surfaces (Fig. 4 (d)). Some of the oxides were embedded in the composites. The damage to the worn disk and pin surfaces appeared to have been caused by the abrasive action of the titanium oxide and silicon oxide and detachment of the embedded oxides from the substrate. These results indicated that tribo-oxidation, abrasion and depression caused by the tribo-oxidation products occurred on the 80Ti-Si-C composite surfaces when slid without lubricant.

Figure 5 shows SEM and EPMA images of the 70Ti-Si-N composite disk and pin worn without lubricant. The worn disk surfaces of 70Ti-Si-N composites were relatively smooth. On the sliding surfaces of Ti-Si-N composites, several pits and plastic flow were observed (Fig.5 (a)). The pits were pores that formed during the sintering and polishing processes. EPMA analysis revealed that the oxygen concentration on the inside of the wear track was higher than that on the unworn surface (Fig. 5 (b)). As shown in Fig. 5 (c), the worn Ti-Si-N composite pin surfaces were smooth. Plastically deformed oxygen rich scales were scattered on the worn pin surfaces. These results indicated that tribo-oxidation occurred and produced oxide deformed on the sliding surfaces of 70Ti-Si-N composite disks.

All the materials we tested underwent tribo-oxidation during sliding without lubricant. Tribo-oxidation product, i.e., titanium oxide, adhered to the sliding surfaces of the titanium. On the sliding surfaces of Ti-Si-C composites, tribo-oxidation products, i.e., titanium oxide and silicon oxide, abraded and hollowed the composite. On the sliding surfaces of Ti-Si-N composites, the tribo-oxidation product deformed plastically. The material loss of the Ti-Si-N composite caused by the tribo-oxidation product was much less than that of the Ti-Si-C composite. Therefore, the wear resistance of the Ti-Si-N composite was higher than that of the Ti-Si-C composite.

\section{Summary}

Titanium metal, composites produced from mixture of $\mathrm{SiC}$ and titanium (Ti-Si-C composites) and composites produced from mixture of $\mathrm{Si}_{3} \mathrm{~N}_{4}, \mathrm{TiN}$ and titanium (Ti-Si-N composites) were slid against themselves without lubricant. The wear resistance increased in the order of titanium metal, Ti-Si-C composites and Ti-Si-N composites. The wear of the composites was influenced by the kind of ceramics in the starting material rather than the amount of the ceramics. Tribo-oxidation occurred on the surfaces of the composites during sliding. The produced oxide abraded and hollowed the Ti-Si-C composite. On the other hand, plastic flow of the oxide was observed on the sliding surface of Ti-Si-N composite. The material loss of the Ti-Si-N composite caused by the tribo-oxidation product was much less than that of the Ti-Si-C composite.

\section{References}

[1] Oh, J. C., Lee, S. and Golkovski, G. M., "Improvement of the Hardness and Wear Resistance of (TiC, TiN)/Ti-6Al-4V Surface-Alloyed Materials Fabricated by High-Energy Electron-Beam Irradiation," Metall. Mater. Trans. A, 32A, 2001, 2995-3005.

[2] Jiang, P., He, X. L., Li, X. X., Yu, L. G. and Wang, H. M., "Wear Resistance of a Laser Surface Alloyed Ti-6Al-4V Alloy," Surf. Coat. Technol., 130, 2000, 24-28.

[3] Vreeling, J. A., Ocelik, V. and De Hosson, J. T. M., "Ti-6Al-4V Strengthened by Laser Melt Injection of WCp Particles," Acta. Mater., 50, 2002, 4913-4924.

[4] Cui, Z. D., Zhu, S. L., Man, H. C. and Yang, X. J., "Microstructure and Wear Performance of Gradient Ti/TiN Metal Matrix Composite Coating Synthesized Using a Gas Nitriding Technology," Surf. Coat. Technol., 190, 2005, 309-313. 
[5] Ocelik, V., Matthews, D. and De Hosson, J. T. M., "Sliding Wear Resistance of Metal Matrix Composite Layers Prepared by High Power Laser," Surf. Coat. Technol., 197, 2005, 303-315.

[6] Alman, D. E. and Hawk, J. A., "The Abrasive Wear of Sintered Titanium Matrix-Ceramic Particle Reinforced Composites," Wear, 225-229, 1999, 629-639.

[7] Pleshakov, E., Senyas'kyi, Ya. and Fillip, R., "Laser Surface Modification of Ti-6Al-4V Alloy with Silicon Carbide," Mater. Sci., 38, 5, 2002, 646-652.

[8] Yamada, T., Tsuzuku, T. and Sato, H., "Development of Superplastic-Formable Titanium Matrix Composites,” J. Japan Inst. Metals, 65, 3, 2001, 207-216.

[9] Hausmann, J. M., Leyens, C. and Kaysser, W. A., "Interaction between Cyclic Loading and Residual Stress in Titanium Matrix Composites," Journal of Materials Science, 39, 2004, 501-509.

[10] S. Ranganath, "A Review on Particulate-Reinforced Titanium Matrix Composites," J. Mater. Sci., 32. 1997, 1-16.

[11] Morgan, A. E., Broadbent, E. K., Ritz, K. N., Sadana, D. K. and Burrow, B. J., "Interaction of Thin Ti Films with $\mathrm{Si}, \mathrm{SiO}_{2}, \mathrm{Si}_{3} \mathrm{~N}_{4}$, and $\mathrm{SiO}_{\mathrm{x}} \mathrm{N}_{\mathrm{y}}$ under Rapid Thermal Annealing," J. Appl. Phys., 64, 1988, 344-353.

[12] Feng, J., Naka, M. and Schuster, J. C., "Reaction Mechanism Between SiC Ceramic and Ti Foil in Solid State Bonding,” J. Japan Inst. Materials, 59, 9, 1995, 978-983.

[13] Polleti, C., Merstallinger, A., Schubert, T., Marketz, W. and Degischer, H. P., "Wear and Friction Coefficient of Particle Reinforced Ti-Alloys," Material-Wissenschaft Werkstofftechnik, 35, 10-11, 2004, 741-749.
[14] Hibi, Y., Murakami, T., Miyake, K. and Sasaki, S., "Influence of Microstructure on the Wear Behavior of SiC-Reinforced Titanium-Matrix Composites Lubricated by Water and by Ethanol," J. Am. Ceram. Soc., 91, 2, 2008, 508-513.

[15] Hibi, Y., Miyake, K., Murakami, T. and Sasaki, S., "Tribological Behavior of SiC-Reinforced $\mathrm{Ti}_{3} \mathrm{SiC}_{2}$-Based Composites under Dry Condition and under Lubricated Condition with Water and Ethanol," J. Am. Ceram. Soc., 89, 9, 2006, 2983-2985.

[16] Hibi, Y. Enomoto, Y., Sato. H. and Sasaki, S., "Titanium-Silicon-Nitrogen Composites with High Wear Resistance in Water and in Artificial Sea Water," J. Am. Ceram. Soc., 85, 9, 2002, 2373-2375.

[17] Hibi, Y., "Tribological Properties and Applications of Titanium-Based Composites in Water," J. Jpn. Soc. Tribologists, 52, 2, 2007, 132-137.

[18] Hibi, Y., Enomoto, Y. and Tanaka, A., "Lubricity of Metal Ethoxide Formed on Sliding Surfaces of $\mathrm{Si}_{3} \mathrm{~N}_{4}$-TiN-Ti Composites in Ethanol," J. Mater. Sci. Lett., 19, 20, 2000, 1809-1812.

[19] Hibi, Y., Enomoto, Y. and Sasaki, S., "Relationship between Wear and Surface Chemical Reactions of Ti Based Composites," Journal of The Surface Science Society of Japan, 23, 7, 2002, 404-410.

[20] Lawn, B. R., Evans, A. G. and Marshall, D. B., "Elastic/Plastic Indentation Damage in Ceramics: The Median/Radial Crack System," J. Am. Ceram. Soc., 63, 9-10, 1980, 574-581.

[21] Nutt, S. R. and Ruff, A. W., "A Study of the Friction and Wear Behavior of Titanium under Dry Sliding Condition," Proc. Wear of Materials, 1983, 426-433.

[22] Budinski, K. G., "Tribological Properties of Titanium Alloys," Proc. Wear of Materials, 1991, 289-299. 